\title{
Analiza rozkładu pacjentów kwalifikowanych do radioterapii z placówek Wielkopolski ze względu na rozpoznanie z uwzględnieniem zachorowalności w regionie
}

\section{Analysis of distribution of patients qualified for radiotheraphy from the Wielkopolska health care units due to diagnosis, taking into account the disease incidence in the region}

\author{
Katarzyna Paczkowska ${ }^{1}$ \\ ${ }^{1}$ Sekcja Koordynacji Pracy Zespołów Interdyscyplinarnych
}

\section{Streszczenie}

Celem pracy było określenie liczby chorych kierowanych do radioterapii do Wielkopolskiego Centrum Onkologii z subregionów wielkopolski (poznański, pilski, koniński, leszczyński, kaliski), i porównanie ze współczynnikiem zachorowalności w roku 2013 w województwie wielkopolskim.

Dane o chorych otrzymano z kart napromieniania oraz systemu informatycznego Eskulap. Badaniem objęto 41 tygodni roku 2013. Stwierdzono lepszą dostępność radioterapii w subregionie poznańskim, w porównaniu do czterech pozostałych subregionów województwa wielkopolskiego: pilskiego, konińskiego, leszczyńskiego i kaliskiego.

\begin{abstract}
Abstrakt
The aim of the study was to estimate the number of patients referred to the Greater Poland Cancer Centre radiotherapy department form Greater Poland subregions (Poznań, Piła, Konin, Leszno, Kalisz) and compare it to the coefficient of cancer incidence in 2013. Patients data were collected from radiation patients' records and from IT system- „Eskulap”. We analysed 41 weeks of the year 2013. We revealed a better access to radiotherapy in Poznań subregion as compared to the four other subregions: Piła, Konin, Leszno and Kalisz.
\end{abstract}

Stowa kluczowe: radioterapia, jednostki kierujące, nowotwory, zachorowalność, dostępność do radioterapii

Keywords: radiotherapy, referring units, cancers, incidence, access to radiotherapy

Katarzyna Paczkowska

Sekcja Koordynacji Pracy Zespołów Interdyscyplinarnych

Wielkopolskie Centrum Onkologii, ul. Garbary 15, 61-866 Poznań, Polska

e-mail: katarzyna.paczkowska@wco.pl 


\section{Wstęp}

Nowotwory złośliwe stanowią istotny problem zdrowotny i ekonomiczny polskiego społeczeństwa biorąc pod uwagę prognozy dotyczące tempa starzenia się populacji polskiej, problem ten będzie narastał. Wielkopolska jest regionem wysokiego ryzyka zachorowania na nowotwory. Każdego roku liczba pacjentów leczonych onkologicznie wzrasta od kilku do kilkunastu procent.

W 2013r. pod względem współczynników standaryzowanych zachorowalności mężczyźni zajmowali 3 miejsce a kobiety 2 pozycję pośród 16 województw [1].

W Wielkopolskim Centrum Onkologii prowadzi się pełne leczenie skojarzone nowotworów: leczenie chirurgiczne, radioterapię, chemioterapię, hormonoterapię. Dlatego pacjenci do WCO , kierowani są przez specjalistów i lekarz rodzinnych z różnych jednostek ochrony zdrowia w Wielkopolsce a także $\mathrm{z}$ innych województw Polski.

\section{Cel}

Celem pracy było zbadanie rozkładu liczby chorych kierowanych do radioterapii w Wielkopolskim Centrum Onkologii, zamieszkałych w różnych subregionach wielkopolski w stosunku do współczynnika zachorowalności w tych subregionach w roku 2013.

\section{Material i metoda:}

Badaniem objęto rok 2013, tygodnie od 1 do 52 (bez uwzględnienia tygodni od 18 do 28 ze względu na brak danych), tj. przeanalizowano łącznie 41 tygodni roku 2013. Informacje o liczbie kierowanych chorych uzyskano z kart napromieniania, oraz z systemu informatycznego Wielkopolskiego Centrum Onkologii.

Otrzymane liczby chorych kierowanych z pięciu subregionów Wielkopolski porównano z współczynnikami zachorowalności zarejestrowanymi w badanych subregionach.

Podregion (subregion, NUTS3) - pojęcie z nomenklatury jednostek terytorialnych do celów statystycznych w Polsce, związane z klasyfikacją NUTS. Jest to jednostka na poziomie regionalnym, których w Polsce od 2008r. jest 66. Każde z województw grupuje kilka podregionów, a podregion grupuje kilka niższych jednostek tj. powiatów. Pojęcie zostało wprowadzone w Polsce w 200or., kiedy wytyczono ich początkowo 44. W latach 2002-2007 stosowano 45 podregionów. Główny Urząd Statystyczny wbrew rozporządzeniom Rady Ministrów stosował także termin subregion.

Na rycinie 1 przedstawiono mapę województwa wielkopolskiego z podziałem na subregiony i powiaty włączone do analizy.

Rycina 1. Mapa województwa wielkopolskiego z podziałem na subregiony i powiaty włączone do analizy.

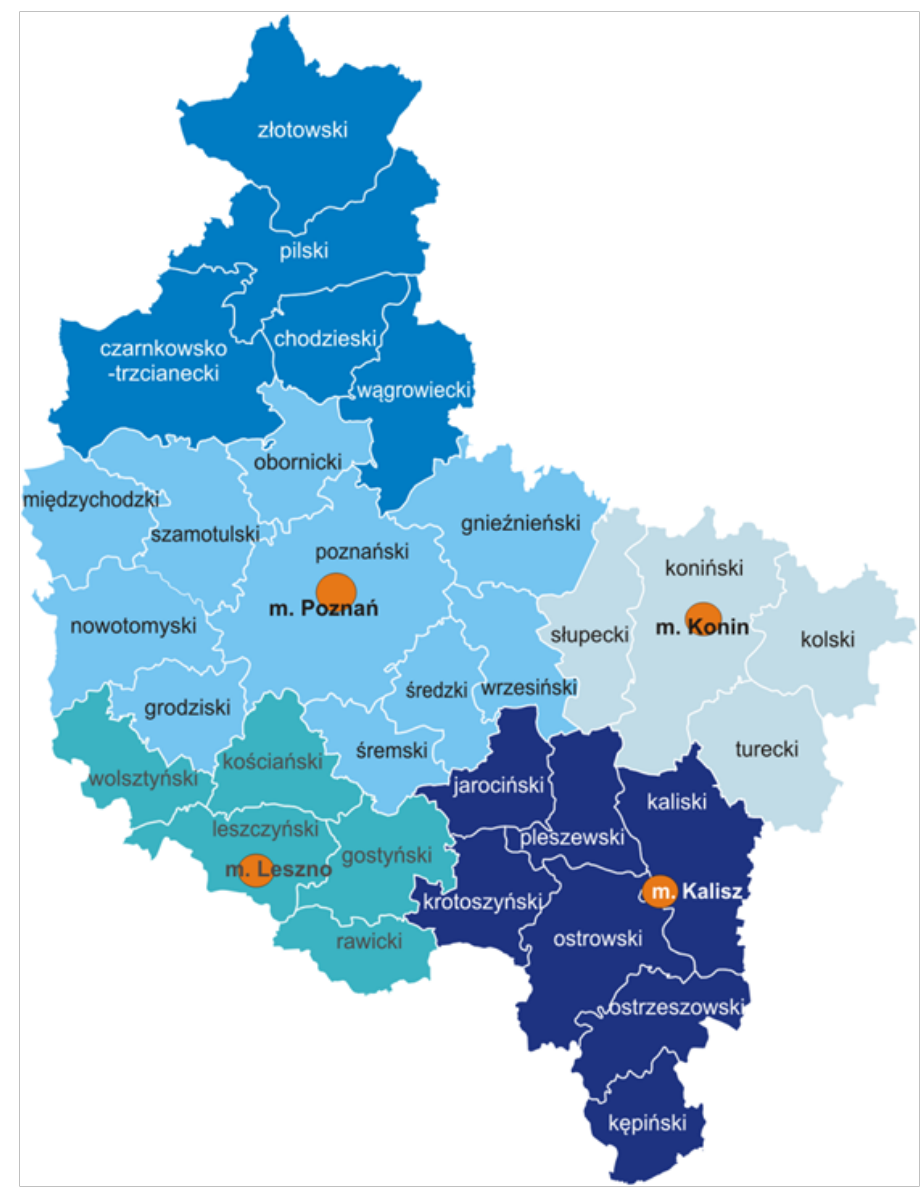


W tabeli 1 przedstawiono liczbę mieszkańców województwa wielkopolskiego w poszczególnych subregionach.

\begin{tabular}{|c|c|}
\hline Subregiony (powiaty )województwa wielkopolskiego & Liczba mieszkańców [tyś] \\
\hline $\begin{array}{c}\text { Poznański ( m. Poznań, poznański obornicki, międzychodzki, } \\
\text { szamotulski, nowotomyski, gnieźnieński, grodziski, śremski, } \\
\text { średzki, wrzesiński) }\end{array}$ & 895,6 \\
\hline $\begin{array}{c}\text { Pilski (złotowski, czarnkowsko - trzciański, } \\
\text { chodzieski, wągrowiecki) }\end{array}$ & 137,6 \\
\hline Koniński (m. Konin, słupecki, kolski, turecki) & 126,2 \\
\hline $\begin{array}{c}\text { Leszczyński (m. Leszno, kościański, wolsztyński, } \\
\text { gostyński, rawicki) }\end{array}$ & 52,2 \\
\hline Kaliski (m. Kalisz, , jarociński, pleszewski, krotoszyński, \\
ostrowski, ostrzeszowski, kępiński)
\end{tabular}

Tabela 1. Liczba mieszkańców w poszczególnych subregionach i powiatach Województwa Wielkopolskiego.

\section{Wyniki}

Łącznie w ciągu 41 tygodni 3755 chorych zostało skierowanych do Wielkopolskiego Centrum Onkologii z pięciu subregionów województwa wielkopolskiego. Standaryzowany współczynnik zachorowalności w całym roku 2013 wyniósł w całej Wielkopolsce 15049.

W tabeli 2 przedstawiono wskaźnik zachorowań na nowotwory według powiatów w całym 2013 roku [1].

\begin{tabular}{|c|c|c|}
\hline Lp. & Nazwa powiatu & Liczba zachorowań \\
\hline 1 & chodzieski & 345 \\
\hline 2 & czarnkowsko-trzcianecki & 587 \\
\hline 3 & gnieźnieński & 321 \\
\hline 4 & gostyński & 208 \\
\hline 5 & grodziski & 254 \\
\hline 6 & jarociński & 247 \\
\hline 7 & kaliski & 231 \\
\hline 8 & kępiński & 309 \\
\hline 9 & kolski & 528 \\
\hline 10 & koniński & 374 \\
\hline 11 & kościański & 303 \\
\hline 12 & krotoszyński & 192 \\
\hline 13 & leszczyński & 128 \\
\hline 14 & międzychodzki & 295 \\
\hline 15 & nowotomyski & 236 \\
\hline 16 & obornicki & 669 \\
\hline 17 & ostrowski & 175 \\
\hline 18 & ostrzeszowski & \\
\hline
\end{tabular}




\begin{tabular}{|c|c|c|}
\hline 19 & pilski & 537 \\
\hline 20 & pleszewski & 1412 \\
\hline 21 & poznański & 203 \\
\hline 22 & rawicki & 217 \\
\hline 23 & słupecki & 398 \\
\hline 24 & szamotulski & 260 \\
\hline 25 & średzki & 303 \\
\hline 26 & śremski & 327 \\
\hline 27 & turecki & 288 \\
\hline 28 & wągrowiecki & 232 \\
\hline 29 & wolsztyński & 352 \\
\hline 30 & wrzesiński & 227 \\
\hline 31 & złotowski & 458 \\
\hline 32 & m. Kalisz & 466 \\
\hline 33 & m. Konin & 293 \\
\hline 34 & m. Leszno & 3206 \\
\hline 35 & m. Poznań & 15049 \\
\hline & Wielkopolska razem & \\
\hline
\end{tabular}

Tabela 2. Liczba zachorowań na nowotwory w Wielkopolsce według powiatów w całym 2013 roku [1]

W tabeli 3 przedstawiono liczby pacjentów skierowanych do Wielkopolskiego Centrum Onkologii w porównaniu z współczynnikami zachorowalności w subregionach wielkopolski, oraz obliczono odsetek chorych, którzy po zachorowaniu na nowotwór w 2013 roku i byli leczeni radioterapią.

\begin{tabular}{|c|c|c|c|c|}
\hline $\begin{array}{c}\text { Subregiony (powiaty) } \\
\text { Wielkopolski }\end{array}$ & $\begin{array}{c}\text { Liczba pacjentów } \\
\text { skierowanych do } \\
\text { radioterapii w } \\
\text { wCO w ciągu 41 } \\
\text { tygodni 2013r. }\end{array}$ & $\begin{array}{c}\text { Zachorowalność } \\
\text { na nowotwory w } \\
\text { całym 2013 roku }\end{array}$ & $\begin{array}{c}\text { Zachorowalność } \\
\text { na nowotwory } \\
\text { w 2013 roku - } \\
\text { symulacja dla } \\
\mathbf{4 1} \text { tygodni roku } \\
\text { 2013r. }\end{array}$ & $\begin{array}{c}\text { Odsetek chorych } \\
\text { którzy po } \\
\text { zachorowaniu } \\
\text { na nowotwór } \\
\text { byli leczeni } \\
\text { radioterapią } \\
\text { w WCO (dla 41 } \\
\text { tygodni roku } \\
\text { 2013r.) }\end{array}$ \\
\hline $\begin{array}{c}\text { Poznański (m. Poznań, } \\
\text { poznański, obornicki, } \\
\text { międzychodzki, } \\
\text { szamotulski, } \\
\text { nowotomyski, } \\
\text { gnieźnieński, } \\
\text { grodziski, śremski, } \\
\text { średzki, wrzesiński) }\end{array}$ & 2370 & 7385 & & \\
\hline $\begin{array}{c}\text { Pilski (złotowski, } \\
\text { czarnkowsko - } \\
\text { trzciański, chodzieski, } \\
\text { wągrowiecki) }\end{array}$ & 302 & & 5823 & \\
\hline
\end{tabular}




\begin{tabular}{|c|c|c|c|c|}
\hline $\begin{array}{c}\text { Koniński (m. Konin, } \\
\text { stupecki, kolski, } \\
\text { turecki) }\end{array}$ & 271 & 1847 & 1456 & $19 \%$ \\
\hline $\begin{array}{c}\text { Leszczyński (m. } \\
\text { Leszno, kościański, } \\
\text { wolsztyński, } \\
\text { gostyński, rawicki) }\end{array}$ & 261 & 1615 & 1273 & $21 \%$ \\
\hline $\begin{array}{c}\text { Kaliski (m. Kalisz, } \\
\text { jarociński, pleszewski, } \\
\text { krotoszyński, } \\
\text { ostrowski, } \\
\text { ostrzeszowski, } \\
\text { kępiński) }\end{array}$ & 270 & 2587 & 2040 & $13 \%$ \\
\hline $\begin{array}{c}\text { Województwo } \\
\text { Wielkolpolskie } \\
\text { (wszystkie powiaty) }\end{array}$ & 3474 & 15049 & 11865 & $29 \%$ \\
\hline
\end{tabular}

Tabela 3. Liczby pacjentów kierowanych do radioterapii w WCO z subregionów województwa wielkopolskiego oraz współczynniki zachorowalności w tych subregionach (analiza 41 tygodni roku 2013).

\section{Dyskusja}

Województwo wielkopolskie jest jednym z największych w Polsce, zarówno pod względem powierzchni (drugie miejsce w kraju 29 826,5 km²) jak i liczby mieszkańców (3 367 016, zajmuje trzecie miejsce po województwie mazowieckim i śląskim). Populację województwa wielkopolskiego w większości stanowią kobiety, na 100 mężczyzn przypada 106 kobiet. W 2013 roku do Wielkopolskiego Rejestru Nowotworów zgłoszono 15049 przypadków nowych zachorowań (7 534 u mężczyzn i 7515 u kobiet). W stosunku do roku 1999 liczba nowych zachorowań wzrosła o 4738 przypadków (tj 46\%).

W Wielkopolsce, podobnie jak w Polsce, występują zjawiska decydujące o wysokim zagrożeniu populacji nowotworami. Są to: ekspozycja na czynniki ryzyka przede wszystkim dym tytoniowy, następnie wciąż niesatysfakcjonująca zgłaszalność na te badania profilaktyczne oraz starzenie się społeczeństwa. W 1999 roku odsetek ludności w wieku powyżej 65 roku życia stanowił 11\% ogółu społeczeństwa, w 2013 było to już 13\%. To oznacza, że nowotwory złośliwe pozostają istotnym wyzwaniem dla zdrowia publicznego [1].

W toku badania zebrano informacje o 3755 pacjentach skierowanych w okresie 41 tygodni 2013 roku do Wielkopolskiego Centrum Onkologii na leczenie radioterapeutyczne, w tym 3474 osób było mieszkańcami województwa wielkopolskiego. Tę liczbę pacjentów porównano z liczbą zachorowań na nowotwory dla 41 tygodni 2013 roku, która wynosi 11865. W ten sposób uzyskano informację o dostępności radioterapii w województwie wielkopolskim. Współczynnik określający stosunek liczby chorych u których zastosowano radioterapię do liczby zachorowań na nowotwory wyniósł, w roku 2013 dla województwa wielkopolskiego wynosi $29 \%$.

W rozbiciu na subregiony wykazano że procentowo stosowano radioterapię u największej liczby chorych na nowotwory spośród mieszkańców subregionu poznańskiego wskaźnik 41\%, w porównaniu z pozostałymi subregionami województwa : pilskim - 24\%, konińskim - $19 \%$, leszczyńskim - 21\% i kaliskim - 13\%.

Zgodnie z europejskim badaniem HERO, odsetek chorych leczonych radioterapią dla Polski wynosi średnio 53\%, co wskazuje że nie wszyscy chorzy z subregionu poznańskiego oraz pozostałych subregionów, byli leczeni radioterapią w WCO. Jest możliwe a nawet prawdopodobne byli leczeni także w innych ośrodkach stosujących radioterapię. W Poznaniu zlokalizowany jest drugi ośrodek radioterapii, co dobrze tłumaczy uzyskany współczynnik 41\% w porównaniu z 53\% uzyskanym w badaniu HERO [7][8].

W pozostałych subregionach województwa wielkopolskiego uzyskano znacznie niższy współczynnik (tab. 3), co świadczy o tym że chorzy z tych subregionów ze względu na odległość do Poznania wybierają leczenie w województwach ościennych. I tak chorzy z subregionu kaliskiego najprawdopodobniej zgłaszają się na 
leczenie do ośrodka onkologicznego Łodzi i Wrocławiu. Możliwe jest również że nie są leczeni wcale lub rezygnują z radioterapii. Podobna sytuacja może występować w subregionie pilskim, ze względu na łatwy dojazd do ośrodka onkologicznego w Bydgoszczy i w subregionie leszczyńskim, z którego chorzy mogą korzystać z radioterapii w Wrocławiu.

Wyniki badania potwierdzają tezę, że w Polsce wciąż znajdują się obszary, na terenie których mieszkańcy nie mają dostępu do niektórych leczniczych świadczeń onkologicznych. Tzw. geograficzne „białe palmy” polskiej onkologii w największym stopniu dotyczą radioterapii oraz w mniejszym, ale tylko nieznacznie chemioterapii, a przede wszystkim innowacyjnej terapii leczniczych[9]. Stopniowe zmniejszanie obszarów „ białych plam” dostępności leczniczych świadczeń onkologicznych w Polsce jest ważnym sposobem na uzyskanie poprawy w zakresie wyników leczenia pacjentów onkologicznych. Zwiększona dostępność do świadczeń o udowodnionej skuteczności i największym wpływie na skuteczne leczenie chorych na nowotwory powinno być jednym z najważniejszych priorytetów polityki zdrowotnej Polski.

Eksperci Instytutu Ochrony Zdrowia rekomendują, aby podstawowymi zasadami modernizowanego systemu lecznictwa onkologicznego były kooperacja, koordynacja, kompleksowość i kompetencja. Rozwój sieci ośrodków radioterapii, który jest w Polsce konieczny dla osiągnięcia lepszych wyników leczenia, przyniesie największy efekt wyłącznie wtedy, gdy u podstawy zmian w polskim systemie ochrony zdrowia zostanie postawiona adekwatnie zorganizowana i finansowana opieka podstawowa oraz diagnostyka, a procesy diagnostyki i terapii będą koordynowane, dla dobra pacjenta, które stanie się centralną wartością tego systemu [9].

\section{Podsumowanie}

Przeprowadzone badanie wskazuje na potencjalnie lepsza dostępność do radioterapii w subregionie poznańskim $41 \%$, biorąc pod uwagę liczbę pacjentów poddanych leczeniu, w porównaniu do zbadanych pozostałych subregionów województwa wielkopolskiego (pilskiego 24 \%, konińskiego 19 \%, leszczyńskiego $21 \%$ kaliskiego $13 \%$ )

Trudno stwierdzić na ile odsetek chorych kierowanych na radioterapię do WCO z województwa wielkopolskiego jest znacznie niższy od wskaźnika uzyskanego w badaniu europejskim HERO, gdyż możliwe jest że znaczna część chorych spoza subregionu poznańskiego korzysta ze świadczeń radioterapii w województwach ościennych.

\section{Konflikt interesu / Conflict of interest}

Nie występuje / None

\section{Etyka / Ethics}

Treści przedstawione w artykule są zgodne z zasadami Deklaracji Helsińskiej, dyrektywami EU oraz ujednoliconymi wymaganiami dla czasopism biomedycznych.

\section{Piśmiennictwo / References}

[1] Nowotwory złośliwe w Wielkopolsce w 2013 roku. Biuletyn nr 12. Poznań 2013:31, Agnieszka DyzmannSroka i inni.

[2] Kordek R. , Jassem J., Krzakowski M., Jeziorski A. Onkologia, Podręcznik dla studentów i lekarzy, Via Medica Gdańsk 2004; 9:46-53.

[3] Malicki J. The importance of accurate treatment planning, delivery, and dose verification Rep Pract Oncol Radiother. 2012; 17(2): 63-65.

[4] Reinfuss M., Byrski E., Malicki J. Radiotherapy facilities, equipment, and staffing in Poland: [WINDOWS-1250]2005-2011. Rep Pract Oncol Radiother 2013;18(3):159-72.

[5] Krzakowski M., Onkologia Kliniczna, tom I. Borgis Wydawnictwo Medyczne, Warszawa 2006; 138-163.

[6] Dyzmann - Sroka A., Malicki J. Cancer incidence and mortality in the Greater Poland Region- Analysis 
of the year 2010 and future trends.

[7] Borras J. M., Barton M., Grau C., Corral J., Verhoeven R., Lemmens V., Eycken L., Henau K., PrimicZakelj M., Strojan P., Trojanowski M., Dyzman - Sroka A., Kubiak A., Gasparotto C., Defourny N., Malicki J., Dunscombe P., Coffey M., Lievens Y. The impact of cancer incidence and stage on optimal utilization of radiotherapy: Methodology of a population based analysis by the ESTRO - HERO project. Radioterapy and Oncology 116 (2015) 45-50.

[8] Borras J. M., Lievens Y., Dunscombe P., Coffey M., Malicki J., Corral J., Gasparotto C., Defourny N., Barton M., Verhoeven R., Eycken L., Primic- Zakelj M., Trojanowski M., Strojan P., Grau C. The optimal utilization proportion of external beam radiotherapy in European countries: An ESTRO- HERO analysis. Radioterapy and Onkology 116 (2015) 38-44.

[9] Kalbarczyk W. P., Brzozowski S. wraz z Zespołem. Stan dostępności do leczniczych świadczeń onkologicznych w Polsce - analiza i rekomendacje. Raport przygotowany dla Polskiego Towarzystwa Onkologicznego. Maj 2015.

[10] Rozporządzenie Rady Ministrów z dnia 14 listopada 2007r. (Dz. U. z 2007r. nr 214,poz. 1573).

[11] Rozporządzenie Rady Ministrów z dnia 13 lipca 200or. ( Dz. U. z 200or.Nr 58, poz. 685).

[12] Rozporządzenie Rady Ministrów z dnia 14 marca 2002r. (Dz. U. z 2002r. Nr 34, poz.311). 